\title{
Analisis Data Log IDS Snort dengan Algoritma Clustering Fuzzy C-Means
}

\author{
Ida Ayu Shinta Dewi Paramitha ${ }^{1}$, Gusti Made Arya Sasmita ${ }^{2}$, I Made Sunia Raharja ${ }^{3}$ \\ Submission: 28-04-2020, Accepted: 20-06-2020
}

\begin{abstract}
Snort is one of open source IDS to detect intrusion or potentially malicious activity on network traffic. Snort will give alert for every detected intrusion and write the alerts in log. Log data in IDS Snort will help network administrator to analyze the vulnerability of network security system. Clustering algorithm such as FCM can be used to analyze the log data of IDS Snort. Implementation of the algorithm is based on Python 3 and aims to cluster alerts in log data into 4 risk categories, such as low, medium, high, and critical. The result of analysis shows that the observed network security system is still vulnerable as IDS Snort records $30 \%$ of medium risk attacks. The evaluation with Modified Partition Coefficient (MPC) obtains clustering validity value of $98 \%$.
\end{abstract}

Intisari- Snort merupakan salah satu sistem deteksi intrusi (IDS) open source yang banyak digunakan untuk mendeteksi intrusi atau aktivitas mencurigakan pada lalu lintas jaringan. Snort akan memberikan alert atau peringatan apabila terdapat serangan yang terdeteksi, kemudian mencatatnya pada log. Data log IDS Snort tersebut dapat digunakan oleh administrator jaringan untuk menganalisis kerentanan sistem keamanan jaringan. Analisis data $\log$ dapat dilakukan dengan berbagai cara, salah satunya mengimplementasikan algoritma clustering seperti Fuzzy C-Means (FCM). Implementasi algoritma pada penelitian ini berbasis Python 3 dan bertujuan untuk mengelompokkan serangan pada data $\log$ menjadi 4 kategori risiko, yaitu low, medium, high, dan critical risk. Hasil analisis menunjukkan bahwa sistem keamanan jaringan yang diamati masih memiliki kerentanan, di mana IDS Snort mencatat adanya 30\% serangan dengan kategori medium risk. Tahap evaluasi dengan Modified Partition Coefficient (MPC) memperoleh validitas clustering mencapai $98 \%$.

Kata Kunci-Clustering, Fuzzy C-Means, Log, Snort.

\section{PENDAHULUAN}

Keamanan kini masih menjadi salah satu masalah dalam perkembangan teknologi, termasuk pada jaringan komputer. Jaringan komputer sebagai bagian dari suatu sistem harus dilindungi dari berbagai jenis ancaman dan serangan, baik yang bersifat aktif maupun pasif. Adapun ancaman dan serangan yang sering terjadi pada jaringan komputer, antara lain adalah DoS, DDoS, scanning, password cracking, dan lainnya.

${ }^{1}$ Mahasiswa, Program Studi Teknologi Informasi Universitas Udayana, Jl. Raya Kampus Udayana, Jimbaran, Badung-Bali, 80361 INDONESIA: 0361-701806; e-mail: 9fshinta27@gmail.com)

2,3 Dosen, Program Studi Teknologi Informasi Universitas Udayana, Jl. Raya Kampus Udayana, Jimbaran, Badung-Bali 80361 INDONESIA (telp: 0361-701806; e-mail: aryasasmita88@gmail.com, sunia.raharja@gmail.com )

I.A. Shinta Dewi P.: Analisis Data Log IDS ...
Beberapa cara dapat dilakukan untuk menjaga aspek keamanan pada jaringan, salah satunya menerapkan sistem deteksi intrusi atau IDS. Kemampuan IDS dalam memberikan alert atau peringatan ketika terdapat intrusi atau aktivitas mencurigakan dapat membantu administrator dalam mengawasi lalu lintas jaringan. Salah satu IDS yang umum digunakan adalah Snort.

Snort merupakan sistem pencegahan dan deteksi intrusi jaringan bersifat open source dengan berbasis aturan (ruledriven) yang digunakan untuk memantau lalu lintas jaringan secara pasif dan memberikan peringatan atau alert ketika ancaman terdeteksi. Sistem ini secara logika dapat dibagi menjadi beberapa komponen yang bekerja sama untuk mendeteksi serangan tertentu. Snort juga mampu menghasilkan output dengan format yang dibutuhkan, seperti data $\log$ yang mencatat alert hasil deteksi [1].

Data $\log$ IDS Snort ini dapat dimanfaatkan oleh administrator jaringan untuk menganalisis performa sistem keamanan jaringan. Data yang tercatat pada log terdiri dari informasi mengenai alert serangan yang berhasil terdeteksi oleh Snort, seperti jenis serangan, waktu serangan, alamat dan port penyerang, serta alamat dan port target penyerang. Snort memberikan dan mencatat alert tersebut sesuai dengan rules atau aturan yang telah dikonfigurasi.

Analisis data $\log$ akan membantu administrator jaringan dalam mengetahui jenis serangan yang masih mampu melewati sistem keamanan jaringan sehingga dapat dilakukan tindakan lebih lanjut dalam mengatasi serangan tersebut. Namun, jumlah data yang tersimpan pada log Snort umumnya cukup besar sehingga ini dapat menjadi masalah karena administrator jaringan membutuhkan banyak waktu untuk menganalisisnya. Pendekatan data mining, seperti klasifikasi dan clustering, dapat digunakan untuk menganalisis data dengan jumlah yang besar.

Analisis $\log$ IDS Snort pernah dilakukan untuk seleksi notifikasi serangan dengan Algoritma K-Means sehingga hanya serangan berbahaya yang akan dikirimkan melalui SMS [2]. Penelitian lainnya melakukan evaluasi K-Means untuk IDPS pada trafik jaringan yang besar dan mendapatkan tingkat akurasi 90\% [3]. Implementasi data mining pada IDS juga pernah dilakukan dengan Naïve Bayes, SVM, dan Random Forest yang mendapatkan hasil akurasi tertinggi oleh Algoritma Random Forest sebesar 98\% [4].

Penelitian ini bertujuan untuk menganalisis data $\log$ IDS Snort dengan algoritma clustering Fuzzy C-Means (FCM). Algoritma FCM dipilih karena menggunakan pemodelan fuzzy yang lebih fleksibel dengan melibatkan derajat keanggotaan, memiliki waktu komputasi yang cepat, dan memiliki keunggulan dalam menghasilkan pusat cluster yang lebih akurat dibandingkan dengan algoritma lainnya [5],[6]. Hasil

p-ISSN:1693 - 2951; e-ISSN: 2503-2372 
clustering berupa jumlah data dan pusat setiap cluster akan digunakan untuk perhitungan nilai risiko sehingga didapatkan persentase jumlah serangan dengan kategori low, medium, high, dan critical risk. Penelitian ini diharapkan dapat membantu administrator dalam menganalisis kerentanan sistem keamanan jaringan di Institusi X.

\section{METODE PENELITIAN}

\section{A. Fuzzy C-Means}

Fuzzy C-Means (FCM) merupakan algoritma clustering dengan logika fuzzy yang keberadaan setiap data ditentukan berdasarkan derajat keanggotaannya. Algoritma FCM diperkenalkan pada 1981 oleh Jim Bezdek. Clustering dengan FCM berbeda dengan teknik klasik, seperti K-Means, di mana setiap data dapat menjadi anggota dari beberapa cluster [7].

Langkah-langkah penyelesaian dengan Algoritma FCM dapat diuraikan sebagai berikut.

1. Masukkan data dengan matriks $X$ berukuran $n \times m(n=$ jumlah data, $m=$ jumlah atribut).

2. Tentukan jumlah cluster $(c)$, pangkat $(w)$, maksimum perulangan (max_iter), error terkecil $(\xi)$, fungsi objektif awal $\left(P_{0}\right)$, dan perulangan awal.

3. Bilangan random $\mu_{i k}$ dibangkitkan sebagai elemen matriks partisi awal. Jumlah setiap kolom kemudian dihitung dengan (1) dan (2).

$Q \boldsymbol{i}=\sum_{k=1}^{c} \mu_{i k}$

$\mu_{i k}=\frac{\mu_{i k}}{Q i}$

4. Pusat cluster ke- $k$ : $V_{k j}$ dihitung dengan (3).

$$
\boldsymbol{V}_{\boldsymbol{k} j}=\frac{\sum_{i=1}^{n}\left(\left(\mu_{i k^{*}}^{*} * X_{i j}\right)\right)}{\sum_{i=1}^{n} \mu_{i k}^{w}}
$$

5. Hitung fungsi objektif pada iterasi ke- $t$ dalam (4).

$$
P_{t}=\sum_{i=1}^{n} \sum_{k=1}^{c}\left(\left|\sum_{j=1}^{m}\left(X_{i j}-V_{k j}\right)^{2}\right| \mu_{i k}^{w}\right)
$$

6. Perubahan matriks partisi kemudian dihitung dalam (5).

$$
\mu_{i k}=\frac{\left|\sum_{j=1}^{m}\left(X_{i j}-V_{k j}\right)^{2}\right|^{\frac{-1}{w-1}}}{\sum_{k=1}^{c}\left|\sum_{j=1}^{m}\left(X_{i j}-V_{k j}\right)^{2}\right|^{\frac{-1}{w-1}}}
$$

7. Periksa kondisi berhenti:

- Apabila $(|P t-P t-1|<\xi)$ atau $(t>$ max_iter) maka iterasi berhenti;

- Apabila tidak sesuai dengan kondisi berhenti, maka: $t=t+1$ dan ulangi langkah ke-4

\section{B. Partition Coefficient Index}

Partition coefficient Index (PCI) digunakan untuk mengukur validasi dari algoritma clustering dengan rentang nilai 0-1, di mana 1 merupakan nilai terbaik dan paling optimal. Persamaan (6) digunakan untuk menghitung PCI [8].

$$
P C I=\frac{1}{N} \sum_{i=1}^{N} \sum_{j=1}^{C} \mu_{i j}^{2}
$$

$N$ merupakan jumlah data, $C$ merupakan jumlah cluster, dan $\mu_{i j}$ merupakan derajat keanggotaan.
Metode evaluasi ini memiliki kelemahan dengan adanya perubahan yang monoton terhadap beragam jumlah cluster. Kelemahan tersebut dapat diatasi dengan Modified Partition Coefficient atau MPC yang dapat dihitung dengan (7) [9].

$$
\operatorname{MPC}(c)=1-\frac{c}{c-1}(1-P C(c))
$$

Sama halnya dengan PCI, nilai MPC memiliki rentang 0-1 di mana jumlah cluster (nilai $c$ ) terbesar menunjukkan nilai yang paling optimal. Nilai yang mendekati 0 menunjukkan keakuratan cluster yang semakin kabur, sedangkan nilai mendekati 1 menunjukkan semakin baik cluster tersebut.

\section{METODOLOGI}

Tahap pertama pada penelitian ini adalah mengumpulkan data dengan memasang IDS Snort pada jaringan Institusi $\mathrm{X}$ selama kurang lebih 1 bulan hingga mendapatkan jumlah data yang cukup. Data dari log tersebut kemudian dikonversi ke format csv untuk lebih mudah untuk diproses di tahap analisis.

Gambar 1: menunjukkan diagram alir untuk tahap analisis pada penelitian ini. Secara garis besar, tahap yang dilakukan adalah pengumpulan dan pencatatan data pada log, preprocessing, pengelompokkan dengan FCM, dan evaluasi.

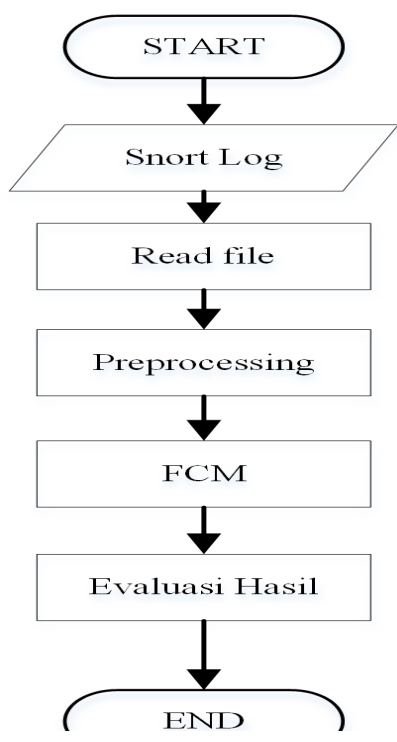

Gambar 1: Diagram alir analisis

Data dari Snort perlu melalui tahap preprocessing untuk menyesuaikan data dengan rentang parameter sehingga dapat diproses dengan algoritma clustering. Atribut yang digunakan pada penelitian ini adalah jenis serangan (classtype), priority, tipe port, dan likelihood. Penentuan label critical, high, medium, dan low dilakukan dengan menghitung risk assesment seperti yang dilakukan pada [10]. Tabel 1 menunjukkan parameter untuk menghitung nilai risiko pada penelitian ini:

TABEL I

PARAMETER PENILAIAN RISIKO

\begin{tabular}{|c|l|}
\hline Parameter & \multicolumn{3}{|c|}{ Deskripsi } \\
\hline Priority & $\begin{array}{l}\text { Priority menentukan tingkat keparahan (severity level) } \\
\text { untuk setiap jenis serangan (classtype). Snort } \\
\text { menyediakan klasifikasi serangan beserta priority tag }\end{array}$ \\
\hline
\end{tabular}




\begin{tabular}{|c|l|}
\hline Parameter & \multicolumn{1}{|c|}{ Deskripsi } \\
\hline Port type & $\begin{array}{l}\text { dengan rentang tingkat keparahan masing-masing. } \\
\text { Penelitian ini menggunakan rentang 1-4, semakin besar } \\
\text { nilainya maka priority semakin tinggi. }\end{array}$ \\
& $\begin{array}{l}\text { Port terdiri dari 3 tipe, yaitu well-known, registered, } \\
\text { dan dynamic [11]. Rentang tipe port well-known (0- } \\
\text { 1023) diberi nilai 3, registered (1024-49151) diberi } \\
\text { nilai 2, dan dynamic (49152-65535) dengan nilai 1. } \\
\text { Penelitian ini menambahkan 1 tipe dengan nilai 4 } \\
\text { untuk port yang paling sering diserang hacker [12]. }\end{array}$ \\
\hline Likelihood & $\begin{array}{l}\text { Nilai likelihood dapat diberikan berdasarkan frekuensi } \\
\text { munculnya suatu alert [13]. Parameter ini memiliki } \\
\text { rentang 1-5, di mana nilai 1 merupakan nilai untuk } \\
\text { alert dengan frekuensi rendah dan nilai 5 untuk } \\
\text { frekuensi tinggi. Penentuan skala frekuensi } \\
\text { menggunakan panduan penilaian risiko dari NIST [14]. }\end{array}$ \\
\hline
\end{tabular}

Parameter pada Tabel 1 akan digunakan untuk memberi label untuk setiap cluster dari algoritma FCM. Persamaan (12) digunakan untuk menghitung nilai risiko (RA) setiap cluster sebagai penentu label [15].

Priority $(\mathrm{P})=[1-4]$

Port Type $(\mathrm{D})=[1-4]$

Likelihood $(\mathrm{L})=[1-5]$

Max RA $=10$

$R A=\frac{P * D * R}{X}$

Nilai risiko (RA) memiliki rentang dengan nilai maksimal 10 sehingga untuk mencari nilai $X$ dengan mengacu pada (9).

$R A=\frac{\operatorname{Max}(\mathrm{P}) * \operatorname{Max}(\mathrm{D}) * \operatorname{Max}(\mathrm{L})}{\mathrm{X}}=10$

$10=\frac{4 * 4 * 5}{\mathrm{X}}$

$X=8$

$R A=\frac{P * D * R}{8}$

Hasil perhitungan RA untuk setiap cluster tersebut kemudian diberi label low, medium, high, dan critical sesuai dengan ketentuan pada Tabel 2.

TABEL II

KATEGORI NILAI RISIKO

\begin{tabular}{|c|c|}
\hline Range & Label \\
\hline $0-3.9$ & Low \\
\hline $4.0-6.9$ & Medium \\
\hline $7.0-8.9$ & High \\
\hline $9.0-10.0$ & Critical \\
\hline
\end{tabular}

Implementasi FCM dan visualisasi jenis serangan pada penelitian ini menggunakan Python 3. Evaluasi dilakukan dengan perhitungan Modified Partition Coefficient (MPC) untuk menentukan validitas hasil clustering.

\section{HASIL DAN PEMBAHASAN}

Jumlah data pada penelitian ini adalah 346509 data dengan 27 atribut sesuai dengan aturan Snort secara default. Potongan dataset tersebut dapat dilihat pada Tabel 3. Data yang telah dikumpulkan perlu untuk melalui tahap preprocessing untuk menambahkan beberapa atribut sesuai dengan parameter penilaian risiko yang telah ditentukan.

\section{A. Preprocessing}

Tahap preprocessing diawali dengan menambahkan classtype atau klasifikasi jenis serangan untuk setiap data menggunakan rules Snort yang telah di-parsing. Penambahan atribut classtype ini dilakukan untuk menentukan nilai priority dengan rentang nilai 1-4. Priority untuk setiap classtype dapat dilihat pada Snort Manual [16].

Atribut lain yang ditambahkan pada tahap ini adalah port type atau tipe port sesuai dengan deskripsi pada Tabel 1. Penambahan nilai likelihood untuk setiap data didasarkan pada frekuensi setiap alert atau alert rate, di mana semakin tinggi frekuensinya maka nilai risikonya juga semakin tinggi.

\section{B. Clustering Fuzzy C-Means}

Data yang telah melalui tahap preprocessing kemudian dikelompokkan dengan FCM untuk mendapatkan hasil cluster dan pusat cluster. Hasil pusat cluster tersebut yang akan digunakan untuk perhitungan nilai risiko.

Langkah awal implementasi FCM adalah penentuan jumlah cluster yang dilakukan dengan rumus MPC untuk mendapatkan jumlah cluster terbaik. Penentuan jumlah cluster dilakukan dengan rentang 2-6, di mana akan dipilih jumlah cluster dengan nilai MPC yang paling mendekati 1 .

Gambar 2: menunjukkan bahwa jumlah cluster atau $c=6$ memiliki nilai MPC yang paling mendekati 1, sehingga clustering pada penelitian ini dilakukan dengan 6 cluster. Maksimum iterasi yang digunakan adalah 300 dan error terkecil yang diharapkan adalah 0,00001 .

TABEL III

POTONGAN DATASET

\begin{tabular}{|c|c|c|c|c|c|c|c|c|c|}
\hline timestamp & sig_gen & sig_id & sig_rev & msg & proto & src & srcport & dst & dstport \\
\hline $\begin{array}{c}11 / 27- \\
12: 47: 01\end{array}$ & 1 & 2402000 & 5371 & $\begin{array}{c}\text { ET DROP Dshield Block Listed } \\
\text { Source group 1 }\end{array}$ & TCP & 89.248 .168 .69 & 41373 & 114.5 .36 .70 & 6777 \\
\hline $\begin{array}{c}11 / 27- \\
12: 48: 11\end{array}$ & 1 & 2403368 & 53375 & $\begin{array}{c}\text { ET CINS Active Threat Intelligence } \\
\text { Poor Reputation IP TCP group 35 }\end{array}$ & TCP & 45.5 .37 .140 & 38156 & 114.5 .36 .70 & 9001 \\
\hline $\begin{array}{c}11 / 27- \\
12: 48: 23\end{array}$ & 1 & 2403450 & 53375 & $\begin{array}{c}\text { ET CINS Active Threat Intelligence } \\
\text { Poor Reputation IP TCP group 76 }\end{array}$ & TCP & 80.82 .70 .239 & 52621 & 114.5 .36 .70 & 3677 \\
\hline $\begin{array}{c}11 / 27- \\
12: 48: 23\end{array}$ & 1 & 2402000 & 5371 & $\begin{array}{c}\text { ET DROP Dshield Block Listed } \\
\text { Source group 1 }\end{array}$ & TCP & 80.82 .70 .239 & 52621 & 114.5 .36 .70 & 3677 \\
\hline$\vdots$ & $\vdots$ & $\vdots$ & $\vdots$ & $\vdots$ & $\vdots$ & $\vdots$ & $\vdots$ & $\vdots$ & $\vdots$ \\
\hline $\begin{array}{c}01 / 06- \\
12: 12: 24\end{array}$ & 1 & 2010935 & 3 & $\begin{array}{c}\text { ET SCAN Suspicious inbound to } \\
\text { MSSQL port 1433 }\end{array}$ & TCP & 114.5 .230 .77 & 56242 & 114.5 .36 .70 & 1433 \\
\hline
\end{tabular}

I.A. Shinta Dewi P.: Analisis Data Log IDS ... 


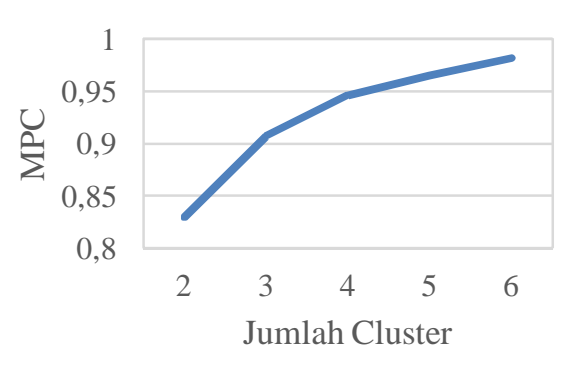

Gambar 2: Perbandingan nilai jumlah cluster

Implementasi FCM pada penelitian ini dilakukan dengan Python 3 menggunakan modul dari PyPi [17] dan mendapatkan hasil berupa jumlah data dan pusat setiap cluster. Tabel 4 berikut menunjukkan jumlah data pada masingmasing cluster:

TABEL IV

JUMLAH DATA SETIAP CLUSTER

\begin{tabular}{|c|c|}
\hline Cluster ke $-\mathbf{i}$ & Jumlah Data \\
\hline 1 & 8421 \\
\hline 2 & 6208 \\
\hline 3 & 17245 \\
\hline 4 & 180431 \\
\hline 5 & 105432 \\
\hline 6 & 28772 \\
\hline
\end{tabular}

Gambar 3: menunjukkan visualisasi jumlah data hasil clustering FCM dengan pie chart. Terlihat bahwa Cluster 4 memiliki jumlah data terbesar dan Cluster 2 memiliki jumlah data terkecil.

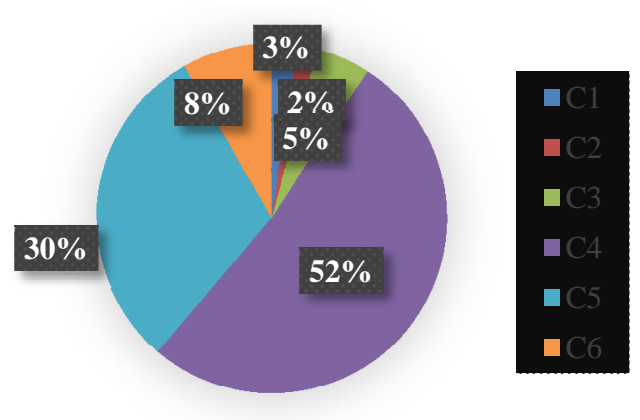

Gambar 3: Hasil clustering FCM

\section{Perhitungan Nilai Risiko}

Perhitungan nilai risiko dilakukan terhadap pusat cluster hasil clustering FCM. Pusat cluster ini mewakili data yang berada pada setiap cluster. Adapun pusat cluster dan perhitungan nilai risikonya (RA) dapat dilihat pada Tabel 5:

TABEL V

PERHITUNGAN NILAI RISIKO

\begin{tabular}{|c|c|c|c|c|c|}
\hline Cluster & P & D & L & RA & Kategori \\
\hline Cluster 1 & 1.016146 & 1.772347 & 1.000000 & 0.23 & Low \\
\hline Cluster 2 & 1.006239 & 3.989993 & 1.000000 & 0.5 & Low \\
\hline Cluster 3 & 2.999490 & 3.971179 & 1.000000 & 1.49 & Low \\
\hline Cluster 4 & 2.000094 & 1.000051 & 2.999332 & 0.75 & Low \\
\hline Cluster 5 & 2.999961 & 3.999668 & 2.999601 & 4.5 & Medium \\
\hline Cluster 6 & 2.998362 & 1.976388 & 1.000000 & 0.74 & Low \\
\hline
\end{tabular}

ISSN $1693-2951$
Hasil perhitungan nilai risiko menunjukkan bahwa data yang berada pada Cluster 1,2,3,4, dan 6 merupakan data dengan kategori low risk, sedangkan data pada Cluster 5 merupakan data dengan kategori medium risk. Visualisasi terhadap perhitungan nilai risiko ini dapat dilihat pada Gambar 4:

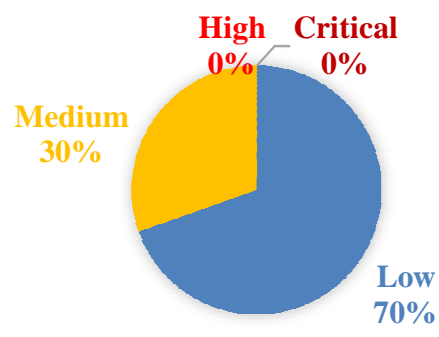

Gambar 4: Hasil perhitungan nilai risiko

\section{Visualisasi Data Log}

Visualisasi data $\log$ dilakukan berdasarkan jenis serangan dan alert rate yang merupakan frekuensi munculnya alert untuk setiap serangan pada data $\log$ IDS Snort. Adapun jenis serangan dan frekuensinya ditunjukkan pada Tabel 6:

TABEL VI

FREKUENSI ALERT JENIS SERANGAN

\begin{tabular}{|c|c|c|c|}
\hline No & Jenis Serangan & Freq & $\begin{array}{l}\text { Alert } \\
\text { Rate }\end{array}$ \\
\hline 1. & ICMP test detected & 180431 & 52.07 \\
\hline 2. & $\begin{array}{l}\text { ET SCAN Suspicious inbound to MSSQL port } \\
1433\end{array}$ & 105432 & 30.43 \\
\hline 3. & ET DROP Dshield Block Listed Source & 17135 & 4.95 \\
\hline 4. & (spp_reputation) packets blacklisted & 14629 & 4.22 \\
\hline 5. & $\begin{array}{c}\text { ET CINS Active Threat Intelligence Poor } \\
\text { Reputation IP TCP }\end{array}$ & 11715 & 3.38 \\
\hline 6. & ET SCAN Potential SSH Scan & 9890 & 2.85 \\
\hline 7. & $\begin{array}{l}\text { ET COMPROMISED Known Compromised or } \\
\text { Hostile Host Traffic TCP }\end{array}$ & 2307 & 0.67 \\
\hline 8. & $\begin{array}{l}\text { ET CINS Active Threat Intelligence Poor } \\
\text { Reputation IP UDP }\end{array}$ & 2025 & 0.58 \\
\hline 9. & ET SCAN Sipvicious Scan & 905 & 0.26 \\
\hline 10. & $\begin{array}{l}\text { ET SCAN Sipvicious User-Agent Detected } \\
\text { (friendly-scanner) }\end{array}$ & 899 & 0.26 \\
\hline 11. & $\begin{array}{l}\text { ET DROP Spamhaus DROP Listed Traffic } \\
\text { Inbound }\end{array}$ & 258 & 0.07 \\
\hline 12. & $\begin{array}{l}\text { ET SCAN Suspicious inbound to mySQL port } \\
\qquad 3306\end{array}$ & 245 & 0.07 \\
\hline 13. & ET SCAN SipCLI VOIP Scan & 231 & 0.07 \\
\hline 14. & $\begin{array}{l}\text { ET SCAN Suspicious inbound to PostgreSQL } \\
\text { port } 5432\end{array}$ & 172 & 0.05 \\
\hline 15. & $\begin{array}{l}\text { ET SCAN Suspicious inbound to Oracle SQL } \\
\text { port } 1521\end{array}$ & 68 & 0.02 \\
\hline 16. & $\begin{array}{l}\text { ET TOR Known Tor Relay/Router (Not Exit) } \\
\text { Node TCP Traffic }\end{array}$ & 41 & 0.01 \\
\hline 17. & $\begin{array}{l}\text { ET INFO UPnP Discovery Search Response } \\
\text { vulnerable UPnP device } 2\end{array}$ & 37 & 0.01 \\
\hline 18. & ET SCAN NMAP OS Detection Probe & 27 & 0.01 \\
\hline 19. & $\begin{array}{l}\text { ET SCAN Suspicious inbound to mSQL port } \\
4333\end{array}$ & 17 & 0 \\
\hline 20. & $\begin{array}{c}\text { ET VOIP Modified Sipvicious Asterisk PBX } \\
\text { User-Agent }\end{array}$ & 16 & 0 \\
\hline 21. & ET COMPROMISED Known Compromised or & 13 & 0 \\
\hline
\end{tabular}

I.A. Shinta Dewi P.: Analisis Data Log IDS ... 


\begin{tabular}{|c|c|c|c|}
\hline No & Jenis Serangan & Freq & $\begin{array}{c}\text { Alert } \\
\text { Rate }\end{array}$ \\
\hline 22. & Hostile Host Traffic UDP & & \\
\hline 23. & $\begin{array}{c}\text { MALWARE-CNC Win.Trojan.ZeroAccess } \\
\text { inbound connection }\end{array}$ & 2 & 0 \\
\hline 24. & ET SCAN Potential VNC Scan 5900-5920 & 2 & 0 \\
\hline 25. & ET VOIP REGISTER Message Flood UDP & 2 & 0 \\
\hline 26. & $\begin{array}{c}\text { ET DOS Possible NTP DDoS Inbound Frequent } \\
\text { Un-Authed MON_LIST Requests IMPL 0x03 }\end{array}$ & 1 & 0 \\
\hline
\end{tabular}

Gambar 5: menunjukkan visualisasi terhadap jenis serangan yang tercatat pada data $\log$ sesuai dengan Tabel 6. Terdapat 26 jenis serangan berbeda dengan alert rate tertinggi adalah "ICMP Test Detected" dengan klasifikasi icmp-event.

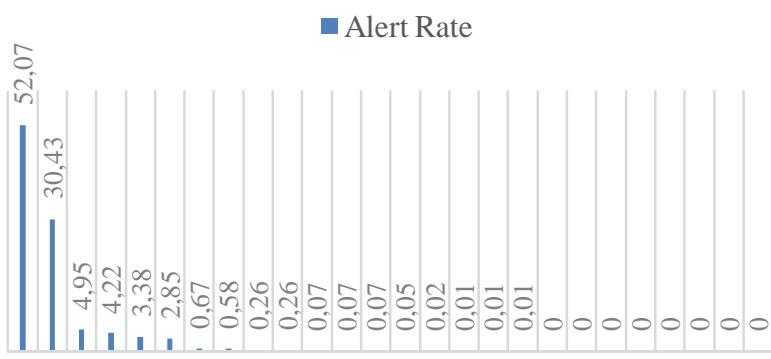

12344567891011121314151617181920212223242526

Gambar 5: Visualisasi data $\log$

\section{E. Evaluasi Algoritma FCM}

Evaluasi dilakukan dengan menghitung validitas clustering menggunakan persamaan MPC terhadap 6 cluster, di mana didapatkan nilai 0,98185802. MPC dihitung berdasarkan derajat keanggotaan setiap data pada hasil clustering iterasi terakhir. Perhitungan ini dilakukan melalui Python 3 dengan mengacu pada (7). Nilai ini menunjukkan bahwa tingkat validitas Fuzzy C-Means untuk analisis data $\log$ IDS Snort adalah $98 \%$.

\section{KESIMPULAN}

Berdasarkan hasil pengujian dan pembahasan yang telah dilakukan dapat disimpulkan beberapa hal sebagai berikut.

1. Jenis serangan dengan frekuensi tertinggi yang tercatat pada data $\log$ IDS Snort adalah "ICMP Test Detected" yang termasuk klasifikasi icmp-event.

2. Perhitungan nilai risiko terhadap hasil clustering menemukan bahwa jumlah serangan terbesar berada pada kategori low risk, yaitu sebanyak 70\%. Serangan dengan kategori medium risk mencapai $30 \%$ dan tidak ada serangan dengan kategori high maupun critical.

3. Evaluasi dengan MPC menunjukkan bahwa Algoritma FCM dapat digunakan untuk analisis data $\log$ IDS Snort dengan tingkat validitas sebesar $98 \%$.

4. Hasil analisis data $\log$ menunjukkan bahwa sistem keamanan jaringan pada Institusi X masih perlu untuk terus dipantau mengingat adanya serangan tingkat medium yang terdeteksi dengan frekuensi yang cukup banyak.

I.A. Shinta Dewi P.: Analisis Data Log IDS ...

\section{REFERENSI}

G. D. Kurundkar, N. A. Naik, and S. Khamitkar, "Network Intrusion Detection using SNORT," Int. J. Eng. Res. Appl., vol. vol.2, no. Issue 2, pp. 1288-1296, 2012.

A. Y. Ananta, "Seleksi Notifikasi Serangan Berbasis Ids Snort Menggunakan Metode K-Means," SMARTICS J., vol. 3, no. 2, pp. 31-37, 2017, doi: 10.21067/smartics.v3i2.1954.

K. Nalavade and B. B. Meshram, "Evaluation of K-Means Clustering for Effective Intrusion Detection and Prevention in Massive Network Traffic Data," Int. J. Comput. Appl., vol. 96, no. 7, pp. 9-14, 2014, doi: 10.5120/16804-6526.

D. Mongkareng, N. A. Setiawan, and A. E. Permanasari, "Implementasi Data Mining dengan Seleksi Fitur untuk Klasifikasi Serangan pada Intrusion Detection System (IDS)," Citee, no. gambar 2, pp. 314-321, 2017.

R. Hadi, I. K. G. D. Putra, and I. N. S. Kumara, "Penentuan Kompetensi Mahasiswa dengan Algoritma Genetik dan Metode Fuzzy C-Means," Maj. Ilm. Teknol. Elektro, vol. 15, no. 2, pp. 101106, 2016, doi: 10.24843/mite.1502.15.

N. Nidyashofa and Deden Istiawan, "Penerapan Algoritma Fuzzy C-Means untuk Pengelompokan Kabupaten / Kota di Jawa Tengah Berdasarkan Status Kesejahteraan Tahun 2015," 6th Univ. Res. Colloq., no. November, pp. 23-30, 2017.

U. M. Pak and B. Darmajaya, "Penentuan Penerima Beasiswa Dengan Algoritma Fuzzy C-Means Di Universitas Megow Pak Tulang Bawang," J. Teknol. Inf. Magister Darmajaya, vol. 1, no. 02, pp. 158-174, 2015.

M. T. A. C. Widiyanto, "Perbandingan Validitas Fuzzy Clustering pada Fuzzy C-Means Dan Particle Swarms Optimazation ( PSO ) pada Pengelompokan Kelas," JISKa, vol. 4, no. 1, pp. 22-37, 2019. M. M. A. Amirah, A. W. Widodo, and C. Dewi, "Pengelompokan Lagu Berdasarkan Emosi Menggunakan Algoritma Fuzzy C-Means," J. Pengemb. Teknol. Inf. dan Ilmu Komput. Univ. Brawijaya, vol. 1, no. 12 , pp. 1526-1534, 2017.

[10] C. El Mostapha, M. Moughit, and Y. I. Khamlichi, "Building an efficient alert management model for intrusion detection systems," Adv. Sci. Technol. Eng. Syst., vol. 3, no. 1, pp. 18-24, 2018, doi: 10.25046/aj030103.

[11] W. Goralski, "User Datagram Protocol," Illus. Netw., pp. 289-306, 2017, doi: 10.1016/b978-0-12-811027-0.00011-4.

[12] K. H. Mchatta, "Ethical Hacking for Beginners ( Tools , Enumeration and Exploitation )," no. July, 2019.

[13] S. G. Kassa, "IT Asset Valuation, Risk Assessment and Control Implementation Model," ISACA, vol. 3, pp. 1-9, 2017.

[14] NIST, "NIST Special Publication 800-30 Revision 1 - Guide for Conducting Risk Assessments," NIST Spec. Publ., no. September, p. 95, 2012, doi: 10.6028/NIST.SP.800-30r1.

[15] E. M. Chakir, M. Moughit, and Y. I. Khamlichi, "An Effecient Method for Evaluating Alerts of Intrusion Detection Systems National School of Applied Sciences USMBA," 2017 Int. Conf. Wirel. Technol. Embed. Intell. Syst., pp. 1-6, 2017, doi: 10.1109/WITS.2017.7934678

[16] M. Roesch, "SNORT Users Manual 2.9.13 The Snort Project," p. 269, 2019.

[17] M. L. D. Dias, "fuzzy-c-means: An implementation of Fuzzy \$C\$means clustering algorithm." 2019.

p-ISSN:1693 - 2951; e-ISSN: 2503-2372 
\{Halaman ini sengaja dikosongkan \} 